\title{
Statistical Modeling for Nanofluid Flow: A Stretching Sheet with Thermophysical Property Data
}

\author{
Alias Jedi 1,*®D, Azhari Shamsudeen ${ }^{1}$, Noorhelyna Razali ${ }^{2}$, Haliza Othman ${ }^{2}$, \\ Nuryazmin Ahmat Zainuri ${ }^{2}$, Noraishikin Zulkarnain ${ }^{3}{ }^{(D)}$, Nor Ashikin Abu Bakar ${ }^{4}$, \\ Kafi Dano Pati ${ }^{5}$ and Thanoon Y. Thanoon ${ }^{6}$
}

1 Department of Mechanical and Manufacturing Engineering, Faculty of Engineering and Built Environment, Universiti Kebangsaan Malaysia, UKM, Bangi, Selangor 43600, Malaysia; azharibs@ukm.edu.my

2 Department of Engineering Education, Faculty of Engineering and Built Environment, Universiti Kebangsaan Malaysia, UKM, Bangi, Selangor 43600, Malaysia; helyna@ukm.edu.my (N.R.); haliza@ukm.edu.my (H.O.); nuryazmin@ukm.edu.my (N.A.Z.)

3 Department of Electrical, Electronic and Systems Engineering, Faculty of Engineering and Built Environment, Universiti Kebangsaan Malaysia, UKM, Bangi, Selangor 43600, Malaysia; shikinzulkarnain@ukm.edu.my

4 Institute of Engineering Mathematics, Universiti Malaysia Perlis, Arau 02600, Malaysia; ashikinbakar@unimap.edu.my

5 Department of Computer Sciences, Faculty of Science, University of Duhok, 1006 AJ Duhok, Iraq; kafi.pati@uod.ac

6 Department of Business Management Techniques, Administrative Technical College-Mosul, Northern Technical University, 09334 Mosul, Iraq; thanoon.younis@ntu.edu.iq

* Correspondence: aliasjedi@ukm.edu.my

Received: 5 September 2019; Accepted: 31 December 2019; Published: 7 January 2020

\begin{abstract}
This paper reports the use of a numerical solution of nanofluid flow. The boundary layer flow over a stretching sheet in combination of two nanofluids models is studied. The partial differential equation that governs this model was transformed into a nonlinear ordinary differential equation by using similarity variables, and the numerical results were obtained by applying the shooting technique. Copper $(\mathrm{Cu})$ nanoparticles (water-based fluid) were used in this study. This paper presents and discusses all numerical results, including those for the local Sherwood number and the local Nusselt number. Additionally, the effects of the nanoparticle volume fraction, Brownian motion $\mathrm{Nb}$, and thermophoresis $\mathrm{Nt}$ on the performance of heat transfer are discussed. The results show that the stretching sheet has a unique solution: as the nanoparticle volume fraction $\varphi(\varphi=0), N t(N t=0.1)$, and $\mathrm{Nb}$ decrease, the rate of heat transfer increases. Furthermore, as $\varphi(\varphi=0)$ and $\mathrm{Nb}$ decrease, the rate of mass transfer increases. The data of the Nusselt and Sherwood numbers were tested using different statistical distributions, and it is found that both datasets fit the Weibull distribution for different values of $N t$ and rotating $\varphi$.
\end{abstract}

Keywords: boundary layer flow; heat transfer; nanofluid; Weibull distribution; Buongiorno model

\section{Introduction}

In recent years, many researchers have investigated stretching plates, which are used in industry for materials such as lubricants and glass fibers. The theory of flow over a stretching plate was first proposed by Crane [1]. Researchers [2] have also analyzed heat transfer over a stretching sheet with a permeable surface. Related studies involving a stretching surface were conducted by Grubka and Bobba [3], Ali [4], Wang [5], and Hayat et al. [6]. Convective heat transfer is a very important property of nanofluids, and the addition of nanoparticles has been found to improve the thermal conductivity. Widely used types of nanoparticles include monotubes, carbide nanoparticles, and metal nanoparticles, 
which can be added to base fluids such as glycol, ethylene, and engine oil. One of the important properties of nanofluids is their ability to enhance the thermal properties of fluids. Nanofluids have numerous applications, including electronics, biomedicine, nuclear reactors, and space technology. Khan [7], Choi [8], Masuda [9], Choi [10], and Wang [11] used nanoparticles to study the thermal conductivity. In the presence of nanoparticles, Wang [12] examined heat transfer and nanofluid flow by using a nanofluid model, which can also be used to study hydromagnetic flow over a permeable sheet [13]. Using a nanofluid model, Bachok [14] studied the effect of two elements in nanofluids, namely, Brownian motion and thermophoresis. These elements have been used to characterize the flow over a permeable surface [15] and an isothermal vertical plate [16]. Flow and heat transfer in turbulent flow were studied by Z. Taghizabeh-Tabari [17], and their results showed that the rate of heat transfer enhancement and pressure drop increment were greater for a plate heat exchanger (PHE) under turbulent flow conditions. Mahian [18] asserted that it is crucial to use measured data for thermophysical properties to predict the heat transfer coefficient with high accuracy. The analysis reported in [19] revealed that the effect of adding nanoparticles to the base fluid has a strong influence on the heat transfer enhancement by increasing the Reynolds number of flows and increasing the heat transfer. Heydari [20] used water as the base fluid and investigated the effect of the volume fraction of nanoparticles $\left(\mathrm{TiO}_{2}\right)$ on the heat transfer and physical properties of the fluid. In a different approach, Hemmat [21] introduced and used a neural network as a powerful tool for estimating the thermophysical properties of nanofluids. The resulting empirical relationship could predict the thermal conductivity coefficient of water-EG- $\mathrm{Al}_{2} \mathrm{O}_{3}$ nanofluid with acceptable precision. Pourfattah [22] numerically investigated the rate of heat transfer enhancement for the flow regime inside a tube. The rotating flow in fluids has also been studied extensively in the past several years. The rotating flow over a stretching sheet is significant in several manufacturing processes, such as the extrusion of plastic sheets, glass blowing, fiber spinning, and continuous molding [23]. Usoicz [24] studied a physical-statistical model that provided highly accurate predictions of the thermal conductivity of nanofluids. Because nanofluids are essential in many applications, understanding their fundamental properties is crucial for exploring their use and potential benefits. Previous studies have demonstrated that the effective enhancement of the base fluid is important for improving its thermal efficiency [25]. Therefore, in this paper, building on previous studies [26,27], we propose combining the two nanofluid equation models developed by Buongiorno [15] and Tiwari and Das [12]. Our objective is to determine the effect of two key parameters: thermophoresis and Brownian motion. The shooting technique was used to obtain the results for the local Sherwood number and local Nusselt number. We present a physical-statistical model, as well as its distribution to predict the thermal conductivity of a fluid containing copper nanoparticles. The proposed model can be used for a wide range of practical applications in further studies on nanofluids.

\section{Problem Formulation}

We consider the three-dimensional free convection boundary layer flow for an area $y>0$ past a stretching sheet, with a stagnation point $x=0$ and conditions for the plane $y=0$. We consider the flow to be incompressible, laminar, and steady. The flow is assumed to have a stretching velocity $U_{W}(x)$ that varies linearly from $x=0$, with $U_{W}(x)=a x$ and $U_{\infty}(x)=b x(a, b$ are constants, with $b>0$ ). The scheme of the physical configuration is depicted in Figure 1. 

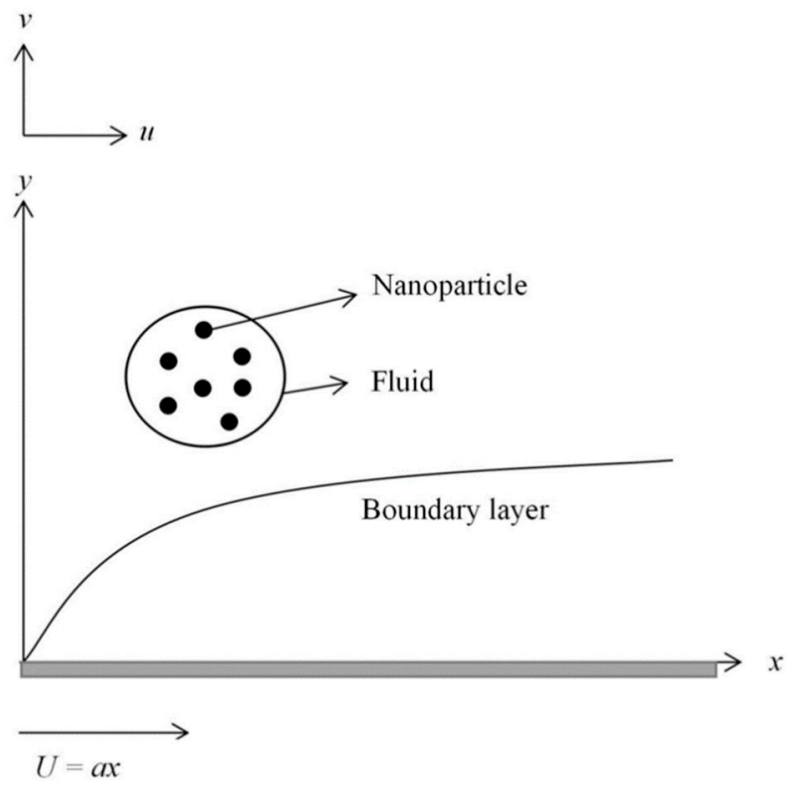

Figure 1. Schematic diagram of the problem.

The same assumption also applies to the velocity of the fluid $U_{\infty}(x)$. The governing equations for a stretching sheet, where $a>b$, are as follows.

$$
\begin{gathered}
\frac{\partial u}{\partial x}+\frac{\partial v}{\partial y}=0 \\
u \frac{\partial u}{\partial x}+v \frac{\partial u}{\partial y}=U_{\infty}(x) \frac{d U_{\infty}}{d x}+\frac{\mu_{n f}}{\rho_{n f}} \frac{\partial^{2} \mu}{\partial y^{2}} \\
u \frac{\partial T}{\partial x}+v \frac{\partial T}{\partial y}=\alpha_{n f} \frac{\partial^{2} T}{\partial y^{2}}+\tau\left[D_{B} \frac{\partial C}{\partial y} \frac{\partial T}{\partial y}+\left(\frac{D_{T}}{T_{\infty}}\right)\left(\frac{\partial T}{\partial y}\right)^{2}\right] \\
u \frac{\partial C}{\partial x}+v \frac{\partial C}{\partial y}=D_{B} \frac{\partial^{2} C}{\partial y^{2}}+\left(\frac{D_{T}}{T_{\infty}}\right) \frac{\partial^{2} T}{\partial y^{2}}
\end{gathered}
$$

subject to

$$
\begin{gathered}
u=U_{w}(x), \quad v=0, \quad T=T_{w}, \quad C=C_{w} \text { at } y=0 \\
u \rightarrow U_{\infty}, \quad T \rightarrow T_{\infty}, C \rightarrow C_{\infty}, \text { as } y \rightarrow \infty
\end{gathered}
$$

where $v$ is the velocity of the component in the $y$-direction, and $u$ is the velocity of the component in the $x$-direction. $T_{w}, T_{\infty}$, and $T$ are the surface temperature, ambient temperature, and temperature, respectively. $C$ is the nanoparticle volume fraction, $C_{\infty}$ is the nanoparticle volume fraction far from the plate, and $C_{w}$ is the nanoparticle volume fraction at the plate. $D_{T}$ is the coefficient of thermophoretic diffusion, and $D_{B}$ is the coefficient of Brownian diffusion. The ratio of heat capacity is $\tau=\left(\rho C_{p}\right)_{s} /\left(\rho C_{p}\right)_{f}$, in which $\left(\rho C_{p}\right)_{s}$ represents the heat capacity of the nanoparticle, and $\left(\rho C_{p}\right)_{f}$ represents the heat capacity of the fluid. Further, $\alpha_{n f}$ is the nanofluid thermal diffusivity, $\mu_{n f}$ is the nanofluid viscosity, and $\rho_{n f}$ is the nanofluid density. These parameters were previously described by Oztop [28].

$$
\begin{gathered}
\alpha_{n f}=\frac{k_{n f}}{\left(\rho C_{p}\right)_{n f}}, \rho_{n f}=(1-\varphi) \rho_{f}+\varphi \rho_{s}, \mu_{n f}=\frac{\mu_{f}}{(1-\varphi)^{2.5}} \\
\left(\rho C_{p}\right)_{n f}=(1-\varphi)\left(\rho C_{p}\right)_{f}+\varphi\left(\rho C_{p}\right)_{s^{\prime}} \frac{k_{n f}}{k_{f}}=\frac{\left(k_{s}+2 k_{s}\right)-2 \varphi\left(k_{f}-k_{s}\right)}{\left(k_{s}+2 k_{s}\right)+\varphi\left(k_{f}-k_{s}\right)}
\end{gathered}
$$


where the parameter $\varphi$ is the nanoparticle volume fraction, $\left(\rho C_{p}\right)_{n f}$ is the heat capacity of the nanofluid, $k_{n f}$ is the thermal conductivity of the nanofluid, $k_{f}$ is the thermal conductivity of the fluid, $k_{s}$ is the thermal conductivity of the solid, $\rho_{f}$ is the fluid density, $\mu_{f}$ is the fluid viscosity, and $\rho_{s}$ is the density of the solid. According to Abu-Nada [25], the term $k_{n f}$ is used for spherical nanoparticles, and its value is negligible for other shapes. Next, given the constraints in Equation (5), the similarity solution of Equations (1)-(4) is computed; Equation (4) was proposed by Buongiorno [15]. We introduce the similarity transformations below.

$$
\eta=\left(\frac{U_{\infty}}{v_{f} x}\right)^{\frac{1}{2}} y, \quad \psi=\left(v_{f} x U_{\infty}\right)^{\frac{1}{2}} f(\eta), \quad \theta(\eta)=\frac{T-T_{\infty}}{T_{w}-T_{\infty}}, \phi(\eta)=\frac{C-C_{\infty}}{C-C_{\infty}}
$$

where $\theta(\eta)$ is a dimensionless variable for temperature, and $\phi(\eta)$ is a dimensionless variable for nanoparticle concentration. The boundary conditions are

$$
\begin{gathered}
u=U_{w}(x), v=0, T=T_{w}, C=C_{w} \text { at } y=0 \\
u \rightarrow U_{\infty}, T \rightarrow T_{\infty}, C \rightarrow C_{\infty} \text { as } y \rightarrow \infty, \\
\frac{1}{(1-\varphi)^{2.5}\left(1-\varphi+\varphi \rho_{s} / \rho_{f}\right)} f^{\prime \prime \prime}+f f^{\prime \prime}-f^{\prime 2}+1=0 \\
\frac{1}{\operatorname{Pr}} \frac{k_{n f} / k_{f}}{\left(1-\varphi+\varphi\left(\rho C_{p}\right)_{s} /\left(\rho C_{p}\right)_{f}\right)} \theta^{\prime \prime}+\frac{1}{2} f \theta^{\prime}+N b \phi^{\prime} \theta^{\prime}+N t \theta^{\prime 2}=0 \\
\phi^{\prime \prime}+\frac{1}{2} L e f \theta^{\prime}+\frac{N t}{N b} \theta^{\prime \prime}=0,
\end{gathered}
$$

subject to the boundary conditions

$$
f(0)=0, f^{\prime}(0)=\varepsilon, \theta(0)=1, \phi(0)=1, f^{\prime}(\eta) \rightarrow 1, \theta(\eta) \rightarrow 0, \phi(\eta) \rightarrow 0 \text { as } \eta \rightarrow \infty
$$

The Brownian motion parameter is

$$
N b=\frac{(\rho c)_{p} D_{B}\left(C_{w}-C_{\infty}\right)}{(\rho c)_{f} v}
$$

the thermophoresis parameter is

$$
N t=\frac{(\rho c)_{p} D_{T}\left(T_{w}-T_{\infty}\right)}{(\rho c)_{f} T_{\infty} v}
$$

the Prandtl number is

$$
\operatorname{Pr}=\frac{v}{\alpha}
$$

the Lewis number is

$$
\operatorname{Pr}=\frac{v}{D_{B}}
$$

the stretching parameter is

$$
\varepsilon=a / b
$$

the skin friction coefficient is

$$
C_{f} R e_{x}^{1 / 2}=\frac{1}{(1-\varphi)^{2.5}} f^{\prime \prime}(0),
$$


the local Nusselt number is

$$
N u_{x} R e_{x}^{-1 / 2}=-\frac{k_{n f}}{k_{f}} \theta^{\prime}(0)
$$

the local Sherwood number is

$$
S h_{x} R e_{x}^{-1 / 2}=-\phi^{\prime}(0),
$$

and the local Reynolds number is

$$
R e_{x}=U x / v_{f}
$$

The data for the Nusselt and Sherwood numbers were tested using the Akaike information criterion (AIC). This test is used to find the goodness of fit and determine the distribution that best fits the data. Table 1 lists the different statistical distributions. For each distribution in the table, the AIC

\begin{tabular}{|c|c|}
\hline Distribution & Cumulative Distribution Function, $F(x)$ \\
\hline Lognormal & $\begin{array}{l}\qquad F(x)=\frac{1}{2}+\frac{1}{2} \operatorname{erf}\left[\frac{\ln (x)-\mu}{\sigma \sqrt{2}}\right] \\
\text { where erf is the complete error function; } \sigma \text { is the shape of the distribution; } x \text { is the value } \\
\text { used to evaluate the function; } \mu \text { is the expected value for the normal distribution. }\end{array}$ \\
\hline Weibull & $\begin{array}{l}\qquad F(x)=1-\exp \left[\left(-\frac{x}{\alpha}\right)^{\beta}\right] \\
\text { where } x \text { is the value used to evaluate the function; } \alpha \text { is the scale parameter; } \beta \text { is the shape } \\
\text { parameter. }\end{array}$ \\
\hline Rayleigh & $\begin{array}{l}\qquad F(x)=1-\exp \left[\left(-\frac{x^{2}}{2 \sigma^{2}}\right)\right] \\
\text { where } x \text { is the value used to evaluate the function; } \sigma \text { is the shape of the distribution. }\end{array}$ \\
\hline Exponential & $\begin{array}{l}\qquad F(x)=1-\exp \left(-\frac{x}{\theta}\right) \\
\text { where } x \text { is the value used to evaluate the function; } \theta \text { is the scale parameter. }\end{array}$ \\
\hline Gamma & $\begin{array}{l}\qquad F(x)=\frac{\gamma\left(\alpha, \frac{x}{\beta}\right)}{\Gamma(\alpha)} \\
\text { where } \Gamma(\alpha) \text { is the incomplete gamma function; } x \text { is the value used to evaluate the } \\
\text { function; } \alpha \text { is the shape parameter; } \beta \text { is the scale parameter. }\end{array}$ \\
\hline $\begin{array}{l}\text { Inverse } \\
\text { Gaussian }\end{array}$ & $\begin{array}{l}\qquad F(x)=\Phi\left[\sqrt{\frac{\lambda}{x}}\left(\frac{x}{\mu}-1\right)\right]+e^{\frac{2 \lambda}{\mu}} \Phi\left[-\sqrt{\frac{\lambda}{x}}\left(\frac{x}{\mu}+1\right)\right] \\
\text { where } x \text { is the value used to evaluate the function; } \Phi \text { denotes the distribution function of } \\
\text { the standard normal; } \mu \text { is the mean; } \lambda \text { is the shape parameter. }\end{array}$ \\
\hline $\begin{array}{l}\text { Inverse } \\
\text { Gamma }\end{array}$ & $\begin{array}{l}\qquad F(x)=\frac{\gamma\left(p, \frac{\beta}{x}\right)}{\Gamma(p)} \\
\text { where } \Gamma(p) \text { is the incomplete gamma function; } x \text { is the value used to evaluate the } \\
\text { function; } \alpha \text { is the shape parameter; } \beta \text { is the scale parameter. }\end{array}$ \\
\hline
\end{tabular}
was calculated, and the best distribution was identified from the AIC values.

Table 1. The distribution test for Nusselt and Sherwood numbers.

The AIC measures the quality of statistical models for a sample set of data. The model that provides the lowest AIC value best fits the data. The formula for the AIC is

$$
A I C=-2 \log (L)+2 k
$$

where $L$ is a model of the likelihood function, and $k$ is the number of parameters.

\section{Results and Discussion}

The shooting technique was used to determine the numerical solutions for Equations (9)-(11) with the boundary conditions in Equation (12). The shooting method converts a boundary value problem (BVP) into an initial value problem (IVP). The main reason for using the shooting method is that it can establish the applicable initial conditions for a related IVP to generate the solution to the BVP. This 
method was applied in the Maple programming language using the "dsolve" command and "shoot" implementation. The influences of $\mathrm{Nb}, \mathrm{N} t$, and $\varphi$ on the heat transfer rate were investigated for $\mathrm{Cu}$ nanoparticles. The values of the thermophysical properties are shown in Table 2.

Table 2. Thermophysical properties of a nanofluid [18].

\begin{tabular}{ccc}
\hline Physical Properties & Base Fluid & Nanoparticle, Cu \\
\hline & Water \\
\hline$C_{p}(J / k g K)$ & 4179 & 385 \\
$\rho\left(k g / m^{3}\right)$ & 997.1 & 8933 \\
$k(W / m k)$ & 0.613 & 400 \\
\hline
\end{tabular}

When $\varphi=0$ for a regular fluid, the range of $\varphi$ should be $0-0.2$ [18]. The value of Pr (Prandtl number) is 6.2. Figure 2a,b depicts the variation in the local Nusselt number and Sherwood number with $N b$ for different $N t$ when $\varphi=0.1, \operatorname{Pr}=6.2, \mathrm{Le}=3$, and $\varepsilon=1.2$ for the stretching case. As clearly shown in Figure $2 \mathrm{a}$, as $\mathrm{Nb}$ increases, the local Nusselt number decreases, while Figure $2 \mathrm{~b}$ shows the opposite trend. Furthermore, Figure $3 \mathrm{a}, \mathrm{b}$ shows that the local Nusselt number and local Sherwood number vary with $N b$ for different $\varphi$ when $\operatorname{Pr}=6.2, N t=0.1, L e=3$, and $\varepsilon=1.2$ for the stretching case. These figures reveal that as $\mathrm{Nb}$ increases, the local Nusselt number and local Sherwood number decrease. It is important to note that the Brownian motion parameter $\mathrm{Nb}$ and thermophoresis $\mathrm{Nt}$ are related to the random motion of nanoparticles $(\mathrm{Cu})$. For small values of $\mathrm{Nb}$ and $\mathrm{Nt}$, the viscosity of the base fluid is weak, and the nanoparticles $(\mathrm{Cu})$ tend to move easily among each other. Because of this phenomenon, the fluid is cooled faster, and the heat transfer rate increases.

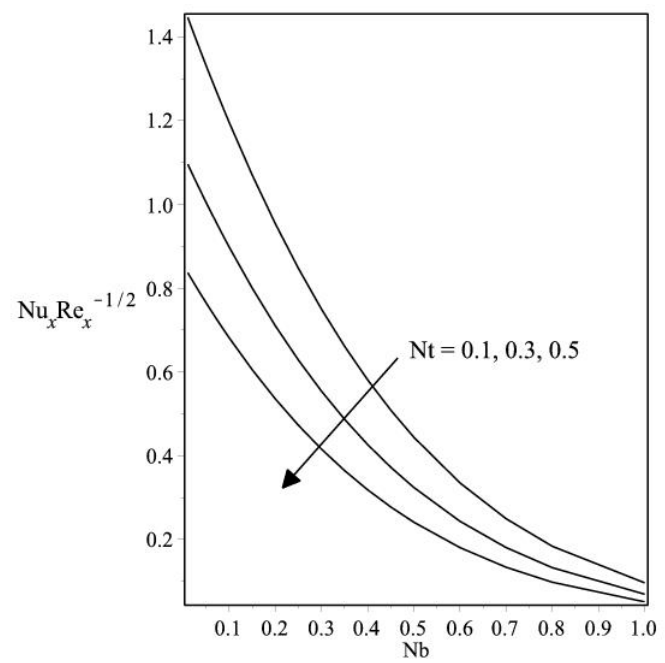

(a)

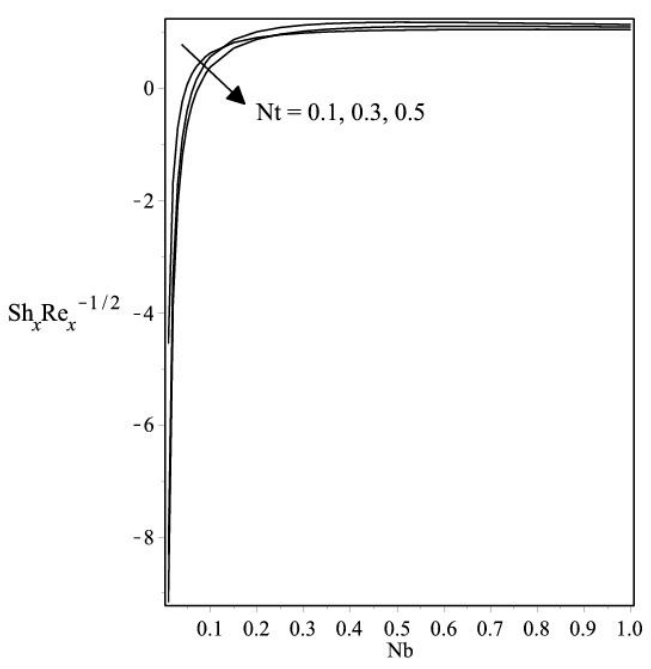

(b)

Figure 2. Variations in (a) the local Nusselt number and (b) the local Sherwood number with $\mathrm{Nb}$ for different $N t$ when $\operatorname{Pr}=6.2, \varphi=0.1 \mathrm{Le}=3$, and $\varepsilon=1.2$ for $\mathrm{Cu}$. 


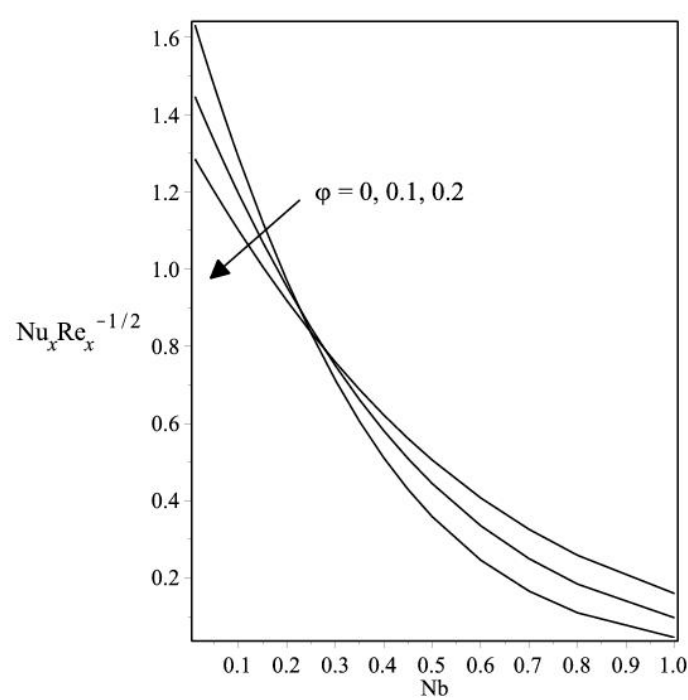

(a)

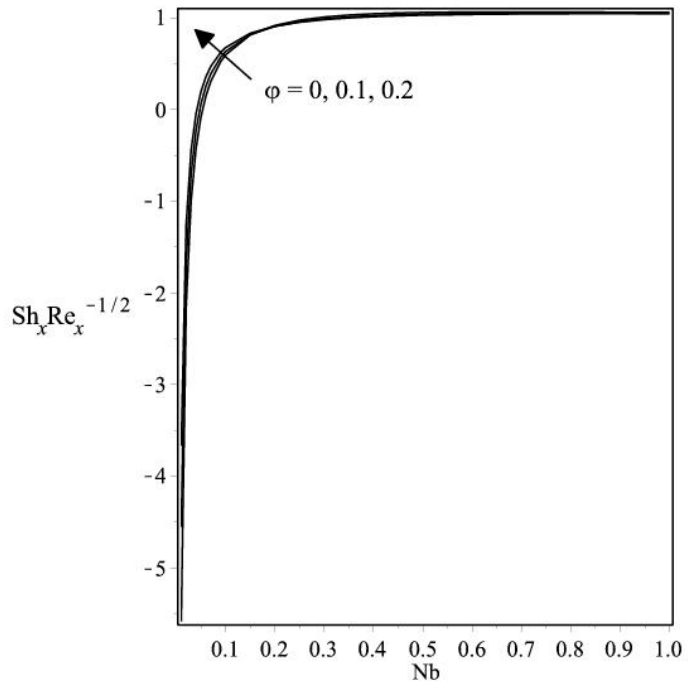

(b)

Figure 3. Variations in (a) the local Nusselt number and (b) the local Sherwood number with $\mathrm{Nb}$ for different $\varphi$ when $\operatorname{Pr}=6.2, \varepsilon=1.2$, Le $=3$, and $N t=0.1$ for $\mathrm{Cu}$.

On the basis of Figures 2 and 3, the data for the Nusselt and Sherwood numbers were further analyzed to obtain the statistical properties for the tested distributions. Tables 3 and 4 show the parameters for different distributions that were tested with the data.

Table 3. Parameters of statistical distributions for the Nusselt number.

\begin{tabular}{|c|c|c|c|c|c|c|c|}
\hline & & \multicolumn{6}{|c|}{ Nusselt } \\
\hline & & \multicolumn{3}{|c|}{$\mathrm{Nt}$} & \multicolumn{3}{|c|}{$\varphi$} \\
\hline & & 0.1 & 0.3 & 0.5 & 0 & 0.5 & 1 \\
\hline \multirow{2}{*}{ Weibull } & alpha & 1.114028 & 0.880117 & 0.707426 & 1.147663 & 1.114028 & 1.060899 \\
\hline & beta & 2.071876 & 2.044809 & 2.03204 & 2.042564 & 2.071873 & 2.107767 \\
\hline \multirow{2}{*}{ Lognormal } & $\mathrm{u}$ & 0.597253 & -0.4527 & -0.6728 & -0.1882 & -0.2134 & -0.257 \\
\hline & sigma & 0.205756 & 0.5687 & 0.5733 & 0.5735 & 0.5581 & 0.5406 \\
\hline Exponential & $\odot$ & 5.958346 & 0.784728 & 0.63081 & 1.023495 & 0.993058 & 0.945277 \\
\hline Rayleigh & $\odot$ & 0.783248 & 0.620077 & 0.498912 & 0.808725 & 0.783248 & 0.743932 \\
\hline \multirow{2}{*}{ Gamma } & alpha & 2.576506 & 2.532032 & 2.512095 & 2.518703 & 2.576506 & 2.645924 \\
\hline & beta & 2.594448 & 3.226632 & 3.9823 & 2.460647 & 2.594448 & 2.799164 \\
\hline \multirow{2}{*}{ InvGaussian } & $\mathrm{u}$ & 0.996058 & 0.784728 & 0.63081 & 1.023495 & 0.993058 & 0.945277 \\
\hline & lambda & 0.585994 & 0.458409 & 0.366933 & 0.594599 & 0.585994 & 0.567803 \\
\hline \multirow{2}{*}{ InvGamma } & $\mathrm{p}$ & 1.128832 & 1.465284 & 1.840917 & 1.141713 & 1.128832 & 1.130869 \\
\hline & beta & 1.561164 & 1.537004 & 1.528137 & 1.520823 & 1.561164 & 1.609246 \\
\hline
\end{tabular}


Table 4. Parameters of statistical distributions for the Sherwood number.

\begin{tabular}{|c|c|c|c|c|c|c|c|}
\hline & & \multicolumn{6}{|c|}{ Sherwood } \\
\hline & & \multicolumn{3}{|c|}{$\mathrm{Nt}$} & \multicolumn{3}{|c|}{$\varphi$} \\
\hline & & 0.1 & 0.3 & 0.5 & 0 & 0.5 & 1 \\
\hline \multirow{2}{*}{ Weibull } & alpha & 0.874411 & 0.898522 & 0.817144 & 0.979489 & 0.874401 & 0.797106 \\
\hline & beta & 2.577703 & 3.371081 & 1.81384 & 3.554751 & 2.577703 & 2.790235 \\
\hline \multirow{2}{*}{ Lognormal } & $\mathrm{u}$ & -0.4244 & -0.3095 & -0.6076 & -0.2249 & -0.4244 & -0.499 \\
\hline & sigma & 0.6062 & 0.2281 & 1.1546 & 0.2703 & 0.6062 & 0.5926 \\
\hline Exponential & $\odot$ & 0.789122 & 0.805275 & 0.74553 & 0.883678 & 0.789712 & 0.723538 \\
\hline Rayleigh & $\odot$ & 1.328239 & 3.12215 & 4.058364 & 1.278631 & 1.328239 & 1.389953 \\
\hline \multirow{2}{*}{ Gamma } & alpha & 2.809859 & 5.54345 & 1.741032 & 5.098837 & 2.809859 & 3.006884 \\
\hline & beta & 3.55806 & 6.883961 & 2.335395 & 5.769994 & 3.55806 & 4.156075 \\
\hline \multirow{2}{*}{ InvGaussian } & $\mathrm{u}$ & 0.789712 & 0.805275 & 0.74553 & 0.883678 & 0.789712 & 0.723538 \\
\hline & lambda & 0.585994 & 0.690534 & 0.210486 & 0.707045 & 0.419399 & 0.380038 \\
\hline \multirow{2}{*}{ InvGamma } & $\mathrm{p}$ & 2.10314 & 0.406664 & 7.750569 & 0.502391 & 2.10314 & 2.441288 \\
\hline & beta & 1.176628 & 3.838668 & 0.628842 & 2.976252 & 1.176628 & 1.121279 \\
\hline
\end{tabular}

Tables 5 and 6 show the Akaike information criteria for the Nusselt and Sherwood numbers. The results show that the lowest AIC values are those for the Weibull distribution. It was also found that as the values of $N t$ and $\varphi$ increase, the AIC values still indicate that the Weibull distribution is optimal.

Table 5. Akaike information criteria (AIC) for the Nusselt number.

\begin{tabular}{|c|c|c|c|c|c|c|c|}
\hline & & \multicolumn{6}{|c|}{ Nusselt } \\
\hline & & \multicolumn{3}{|c|}{$\mathrm{Nt}$} & \multicolumn{3}{|c|}{$\varphi$} \\
\hline & & 0.1 & 0.3 & 0.5 & 0 & 0.5 & 1 \\
\hline Weibull & AIC & 28.0644 & 19.87677 & 12.15149 & 29.47854 & 28.0644 & 25.89071 \\
\hline Lognormal & AIC & 489.2136 & 32.11579 & 24.22703 & 41.67786 & 40.65745 & 38.98349 \\
\hline Exponential & AIC & 72.25254 & 29.27293 & 21.41297 & 38.83604 & 37.7492 & 35.97403 \\
\hline Rayleigh & AIC & 28.09332 & 19.88825 & 12.15742 & 29.4889 & 28.09332 & 25.95421 \\
\hline Gamma & AIC & 130.558 & 155.573 & 181.8519 & 121.6317 & 130.558 & 143.5579 \\
\hline InvGaussian & AIC & 43.14529 & 34.74409 & 26.90818 & 44.40187 & 43.14529 & 41.17968 \\
\hline InvGamma & AIC & 66.38085 & 61.39603 & 59.74171 & 64.92191 & 66.38085 & 68.1083 \\
\hline
\end{tabular}

Table 6. Akaike information criteria (AIC) for the Sherwood number.

\begin{tabular}{|c|c|c|c|c|c|c|c|}
\hline & & \multicolumn{6}{|c|}{ Sherwood } \\
\hline & & \multicolumn{3}{|c|}{$\mathrm{Nt}$} & \multicolumn{3}{|c|}{$\varphi$} \\
\hline & & 0.1 & 0.3 & 0.5 & 0 & 0.5 & 1 \\
\hline Weibull & AIC & 12.54905 & 5.472407 & 13.72022 & 8.515101 & 12.54905 & 8.096197 \\
\hline Lognormal & AIC & 26.92753 & 33.11634 & 23.53942 & 38.58843 & 26.92753 & 23.25246 \\
\hline Exponential & AIC & 23.38957 & 19.23543 & 17.53949 & 26.53744 & 23.38957 & 19.58635 \\
\hline Rayleigh & AIC & 35.5429 & 59.7277 & 77.45971 & 29.54075 & 35.5429 & 36.12442 \\
\hline Gamma & AIC & 146.2801 & 361.4002 & 51.51091 & 377.5105 & 146.2801 & 164.1227 \\
\hline InvGaussian & AIC & 29.30123 & 20.50199 & 29.48493 & 28.73508 & 31.16536 & 27.70555 \\
\hline InvGamma & AIC & 40.39328 & 131.3749 & 210.1284 & 119.6908 & 40.39328 & 38.24802 \\
\hline
\end{tabular}




\section{Conclusions}

Nanofluid flow past a stretching sheet and the influences of parameters $N b, N t$, and $\varphi$ were examined and studied. From this investigation, a unique solution was obtained for the stretching sheet. It was found that as $\mathrm{Nb}$ and $\mathrm{Nt}$ decrease, the rate of heat transfer increases, but the rate of mass transfer decreases. The case is different when $\varphi$ decreases: $N b$ decreases, and the rates of heat and mass transfer decrease. These results show that for different $N t$ and $\varphi$, the Weibull distribution best fits both the Nusselt and Sherwood data.

Author Contributions: A.J. in charge of writing the original draft and editing. A.S. supported on conceptualization. N.R. act as project administration. H.O. run software for analysis. N.A.Z. provided data curation. N.Z. do validation of results. N.A.A.B. in charge of review and editing. K.D.P., T.Y.T. are in charge of formal analysis. All authors have read and agreed to the published version of the manuscript.

Funding: This research was funded by Universiti Kebangsaan Malaysia, grant number GGPM-2017-036.

Acknowledgments: The authors warmly thank the reviewers for their time spent in reading the manuscript and for their valuable comments and suggestions.

Conflicts of Interest: The authors declare no conflict of interest.

\section{References}

1. Crane, L.J. Flow past a stretching plate. Z. Angew. Math. Phys. 1970, 21, 645-647. [CrossRef]

2. Gupta, P.S.; Gupta, A.S. Heat and mass transfer of a continuous stretching surface with suction or blowing. Can. J. Chem. Eng. 1977, 55, 74-76. [CrossRef]

3. Grubka, L.G.; Bobba, K.M. Heat transfer characteristics of a continuous stretching surface with variable temperature. ASME J. Heat Transfer 1985, 107, 248-250. [CrossRef]

4. Ali, M.E. Heat transfer characteristics of a continuous stretching surface. Warme Stoffubertragung 1994, 29, 227-234. [CrossRef]

5. Wang, C.Y. Analysis of viscous flow due to a stretching sheet with surface slip and suction. Nonlinear Anal. Real World Appl. 2009, 10, 375-380. [CrossRef]

6. Hayat, T.; Javed, T.; Abbas, Z. Slip flow and heat transfer of a second grade fluid past a stretching sheet through a porous space. Int. J. Heat Mass Transfer 2008, 51, 4528-4534. [CrossRef]

7. Khan, W.A.; Pop, I. Boundary layer flow of a nanofluid past a stretching sheet. Int. J. Heat Mass Transfer 2010, 53, 2477-2483. [CrossRef]

8. Choi, S.U.S. Enhancing thermal conductivity of fluid with nanoparticles. In Proceedings of the ASME International Mechanical Engineering Congress and Exposition, San Francisco, CA, USA, 12-17 November 1995; pp. 99-105.

9. Masuda, H.; Ebata, A.; Teramae, K.; Hishinuma, N. Alteration of thermal conductivity and viscosity of liquid by dispers- ing ultra-fine particles. Netsu Bussei 1993, 7, 227-233. [CrossRef]

10. Choi, S.U.S.; Zhang, Z.G.; Yu, W.; Lockwood, F.E.; Grulke, E.A. Anomalous thermal conductivity enhancement in nanotube suspensions. Appl. Phys. Lett. 2001, 79, 2252-2254. [CrossRef]

11. Wang, X.-Q.; Mumjudar, A.S. Heat transfer characteristics of nanofluids: A review. Int. J. Therm. Sci. 2007, 46, 1-19. [CrossRef]

12. Tiwari, R.K.; Das, M.K. Heat transfer augmentation in a two-sided lid-driven differentially heated square cavity utilizing nanofluids. Int. J. Heat Mass Transfer 2007, 50, 2002-2018. [CrossRef]

13. Kameswaran, P.K.; Narayana, M.; Sibanda, P.; Murthy, P.V.S.N. Hydromagnetic nanofluid flow due to a stretching or shrinking sheet with viscous dissipation and chemical reaction effects. Int. J. Heat Mass Transfer 2012, 55, 7587-7595. [CrossRef]

14. Bachok, N.; Ishak, A.; Pop, I. Stagnation-point flow over a stretching/shrinking sheet in a nanofluid. Nanoscale Res. Lett. 2011, 6, 623-633. [CrossRef] [PubMed]

15. Boungiorno, J. Convective transport in nanofluids. ASME J. Heat Transfer 2006, 128, 240-250. [CrossRef]

16. Bachok, N.; Ishak, A.; Pop, I. Boundary layer stagnation-point flow toward a stretching/shrinking sheet in a nanofluid. J. Heat Transfer 2013, 135, 054501. [CrossRef] 
17. Taghizadeh-Tabari, Z.; Heris, S.Z.; Moradi, M.; Kahani, M. The study on application of $\mathrm{TiO}_{2} /$ water nanofluid in plate heat exchanger of milk pasteurization industries. Renew. Sustain. Energy Rev. 2016, 58, 1318-1326. [CrossRef]

18. Mahian, O.; Kianifar, A.; Heris, S.Z.; Wongwises, S. Natural convection of silica nanofluids in square and triangular enclosures: Theoretical and experimental study. Int. J. Heat Mass Transfer 2016, 99, 792-804. [CrossRef]

19. Rezaei, O.; Akbari, O.A.; Marzban, A.; Toghraie, D.; Pourfattah, F.; Mashayekhi, R. The numerical investigation of heat transfer and pressure drop of turbulent flow in a triangular microchannel. Phys. E Low-Dimens. Syst. Nanostruct. 2017, 93, 179-189. [CrossRef]

20. Heydari, M.; Toghraie, D.; Akbari, O.A. The effect of semi-attached and offset mid-truncated ribs and Water $/ \mathrm{TiO}_{2}$ nanofluid on flow and heat transfer properties in a triangular microchannel. Therm. Sci. Eng. Prog. 2017, 2, 140-150. [CrossRef]

21. Hemmat, M.E.; Ahangar, M.R.H.; Toghraie, D.; Hajmohammad, M.H.; Rostamian, H.; Tourang, H. Designing artificial neural network on thermal conductivity of $\mathrm{Al}_{2} \mathrm{O}_{3}$-water-EG (60-40\%) nanofluid using experimental data. J. Therm. Anal. Calorim. 2016, 126, 837. [CrossRef]

22. Pourfattah, F.; Motamedian, M.; Sheikhzadeh, G.; Toghraie, D.; Akbari, O.A. The numerical investigation of angle of attack of inclined rectangular rib on the turbulent heat transfer of Water- $\mathrm{Al}_{2} \mathrm{O}_{3}$ nanofluid in a tube. Int. J. Mech. Sci. 2017, 131-132, 1106-1116. [CrossRef]

23. Bakar, N.A.A.; Bachok, N.; Arifin, N.M. Rotating Flow Over a Shrinking Sheet in Nanofluid Using Buongiorno Model and Thermophysical Properties of Nanoliquids. J. Nanofluids 2017, 6, 1-12. [CrossRef]

24. Usowicz, B.; Usowicz, J.B.; Usowicz, L.B. Physical-Statistical Model of Thermal Conductivity of Nanofluids. J. Nanomater. 2014, 2014, 756765. [CrossRef]

25. Abu-Nada, E. Application of nanofluids for heat transfer enhancement of separated flow encountered in a backward facing step. Int. J. Heat Fluid Flow 2008, 29, 242-249. [CrossRef]

26. Nadeem, A.S.; Rehman, U.; Mehmood, R. Boundary Layer Flow of Rotating Two Phase Nanofluid Over a Stretching Surface. Heat Transfer.-Asian Res. 2016, 45, 285. [CrossRef]

27. Rosali, H.; Ishak, A.; Nazar, R.; Pop, I. Rotating flow over an exponentially shrinking sheet with suction. J. Mol. Liquids 2015, 211, 965-969. [CrossRef]

28. Oztop, H.F.; Abu-Nada, E. Numerical study of natural convection in partially heated rectangular enclosures filled with nanofluids. Int. J. Heat Fluid Flow 2008, 29, 1326-1336. [CrossRef] 